\title{
INCLUSION OF HIV EDUCATION INTO A THIRD-YEAR \\ COMMUNICATION COURSE FOR STUDENTS OF \\ ENGINEERING AND THE BUILT ENVIRONMENT
}

\section{J. English*}

Professional Communication Studies, Faculty of Engineering and the Built Environment, e-mail: jane.english@uct.ac.za

\section{S. Alves*}

HIVIAIDS, Inclusivity \& Change Unit

e-mail: sianne.abrahams@uct.ac.za

*University of Cape Town

Cape Town, South Africa

\section{ABSTRACT}

University graduates enter the workplace having immediate influence and, frequently, progress rapidly to managerial positions. The knowledge-sharing space a university allows can go beyond set curricula to ensure these graduates acquire information on and develop appropriate attitudes to health and social problems into the workplace. Five streams of engineers and construction students were asked to volunteer for a six-month pilot study as part of their Professional Communication Studies course. The study was aligned with the aims of the National Strategic Plan for HIV, STIs and TB (2012-2016) which addresses the structural, social, economic and behavioural factors driving the HIV and TB epidemics. The study sample consisted of 41 students, out of a group of 56, who voluntarily attended a weekend workshop and presented their research on the topic of HIV. Results indicated that while the majority of students were knowledgeable about the infection, transmission and treatment options, there was incorrect knowledge concerning other issues such as stigma and workplace discrimination. Conclusions described the experience as positive and reported that the debates in the focus groups on social and public issues were valued. The group's recommendation was that this theme and the assignment should be included in the core course and not be a voluntary additional item.

Keywords: H\&S education, HIVIAIDS, graduateness, engineering education

\section{INTRODUCTION}

This article looks critically at the experience of teaching about HIV and AIDS in the Faculty of Engineering and the Built Environment (EBE) at the University of Cape Town. Because of the nature of the construction industry, especially its history of sourced labour, construction 
work has had, and continues to have a particularly high prevalence of HIV. For this reason, it was deemed important to the university and the faculty to deepen students' understanding of HIV and AIDS.

The work undertaken aims to increase discipline-specific knowledge and awareness of HIV and AIDS. The context of the study is given through a description of the higher education drivers; of literature pertaining to HIV and AIDS in South African education and in the construction industry; of the departments within the university; of the courses through which the study was conducted and of the outcomes of the study and conclusions drawn from them. The drivers were the Higher Education HIV and AIDS Programme (HEAIDS), which was established by the Department of Higher Education and Training (DHET) to assist universities in their programmatic responses to HIV and the University of Cape Town (UCT). HEAIDS (2006) provides frameworks for policy and intervention for use by the universities to upgrade or develop the university's HIV programmes.

The HIV/AIDS, Inclusivity \& Change Unit (HAICU) works within the Transformation Office at UCT. HAICU's mandate is to create platforms for student engagement on areas aligned with the universities strategic initiatives, namely: climate change, safety and violence, transformation and poverty. Under the framework of engaged scholarship, discursive lecture and co-curricula spaces are created for students to discuss the intersectionality of public health and social justice issues within their discipline. HAICU reports annually to the UCT Council and provides programmatic information to HEAIDS (HIV/AIDS Report to Council, March 2014.)

\section{BACKGROUND TO THE HAICU PROGRAMME}

In 2012, approximately 6.5 million people were considered to be HIV positive in South Africa, with the prevalence being highest among people in their twenties (Simbayi, Shisana, Rehle, Onoya, Jooste, Zungu, Labadarios and Zuma 2014). Given that this is the age group of students in which many fall, it makes sense for awareness education and intervention to take place at tertiary institutions. This view was formalised at a South African Universities ViceChancellors Association (SAUVCA) ${ }^{1}$ workshop in 2000 (HEAIDS 2010a).

An outcome of this research was that learning within a learner-centred environment is more effective than within a teacher-centred environment. This applies particularly to social issues (Mkize, Bennett, Reddy and Moletsane 2010). In its policy on the subject, UCT describes curriculum integration of HIV education as a commitment to combat the disease and its related social consequences, through its curriculum, thereby enhancing awareness and 
preparing students for a career. In the HEAIDS report (HEAIDS 2010a), a description of a senior manager with a background in engineering emphasises the importance of graduates having empathy for HIV positive employees. A further finding was that new graduates appeared particularly ill-equipped to deal with HIV and AIDS, despite many believing they were well versed in the subject. Indeed, the gap in students' knowledge about the relevance of HIV education in relation to industry was detailed below:

Everybody believes that because they have heard so much about HIV and AIDS in the mass media and in the printed media they are competent in dealing with HIV and AIDS. Information on HIV and AIDS has become boring. Yet as soon as the new graduates are exposed to the company's HIV and AIDS Champions program, the overwhelming feedback has been: 'My God, I didn't realize', so there's a lot of assumed knowledge which is probably at best half baked, at worst there is total ignorance. (HEAIDS 2010a, 36).

HEAIDS (2010a) concluded in light of this, that higher education institutions need to deliver HIV education and awareness programmes. The HEAIDS report (2010a) described the need for a clear mandate to address HIV and AIDS within curricula so that it did not remain an unexamined and thus weak part of the course. It noted that while many faculties and departments work included aspects of such training, it was too diffuse to be effective.

Lesley Wood (HEAIDS 2014), in her desktop review of HIV and AIDS curricular responses in the higher education sector, concluded that HIV and AIDS education needs to be discipline specific. Wood (HEAIDS 2014) argues that this cannot be achieved by crossdepartment, independent courses but only by integration into core curricula. She also found that lectures without debate lack impact and recommends that lectures need to be backed up by the student being practically involved.

Furthermore, core curricular academics found it too demanding to incorporate an area not in their field, into their courses. Therefore, a different model was needed, which was sought through designated units within universities. At UCT, HAICU's work includes development of curricula and co-curricula, education and evaluation, and development of policy.

In terms of managing curricula that includes HIV education, leadership by the appropriate body at the development level is important to ensure all relevant material is included. Particularly important is that material addressing stigma be included, such as stereotyping and personal biases. Such input should lead to graduates having increased empathy towards HIV positive employees and generally to the reduction of the stigma around it.

At UCT, Volks (2012) showed that including HIV education in core curricula was 
effective. A programme run in the Faculties of Health Sciences and Science had positive outcomes. The programme showed, in particular, that a compulsory module on HIV education was not information-overload but rather contributed to students' knowledge and led to a change in attitudes. HAICU had, at this stage, also done work in the Faculties of Law and Commerce although not in the Faculty of Engineering and the Built Environment. A study by the UCT Alumni office showed that 60 per cent of students from engineering and the built environment and commerce go into management positions and therefore would have the decision-making role and responsibility to drive this area of health and safety. Thus, inclusion of the Faculty of EBE was desirable. Nonetheless, that meant overcoming certain immediate challenges: finding space in an already packed curriculum and integrating it into core course material in these technical degrees.

\section{BACKGROUND TO PROFESSIONAL COMMUNICATION STUDIES}

Students in UCT's EBE faculty take degrees in either Engineering (Chemical, Electrical, Mechanical and Civil) or the Built Environment (Architecture, Town Planning, Construction and Property Studies). It is an accepted part of university curricula now that formerly entirely technical degrees, such as construction and engineering, include communication courses (Reave 2004; Jennings and Ferguson 1995). As part of their degrees, all EBE students take a course in the Professional Communication Studies (PCS) department. PCS courses develop graduate skills by improving students' oral, written and interpersonal communication skills. While the focus is to aid them in their future careers, it also assists them in performing more effectively while at the university (Sulcas and English 2010). The PCS curriculum thus reflects increasing international recognition of the need to have communication competence in virtually all fields of industry. To meet industry's needs, there is growing emphasis, in particular, on communication in engineering curricula (Dannels 2002). Many tertiary institutions across the world now offer communication courses as part of engineering and built environment degrees. For example, in a 2004 study on technical communication instruction in engineering schools, Reave (2004) determined that of the 73 top-ranked US and Canadian engineering schools, about 50 per cent of the US schools and 80 per cent of the Canadian schools required that students complete a course in technical communication (Reave 2004, 452).

Some of the universities in Reave's study, which acknowledged that students should be exposed to communication skills, chose to hand over the responsibility of these courses to departments of psychology, sociology and the humanities (Reave 2004). The components of 
effective communication differ from discipline to discipline and from profession to profession and thus the delivering body must be aware of the different disciplines' needs, be it professional or social.

The HEAIDS report (2010a) describes how communication is important in managing HIV and AIDS. Important too was that the HIV education intervention be housed with a sympathetic subject (Campbell and Cornish 2010). UCT has a designated Professional Communication Studies (PCS) unit which teaches written, spoken, and interpersonal skills, and ethics. PCS was selected as the department to work with HAICU as all EBE students take a one-semester course in PCS in their third year. Competency in negotiation skills, effective listening, decision-making skills forms part of the Professional Communication course, thus further making it an appropriate platform for an AIDS awareness programme. These findings were supported by the results from an engineering task force study which rated 'effectiveness in communicating ideas' as being of importance (Dannels 2002, 256). Communication skills are a core requirement in the effective management of HIV and AIDS - as reflected both in the literature and in this study.

Combining knowledge areas and skills, the departments of HAICU and PCS, reinforced the idea that team teaching is effective because more information is provided to the students without the course lecturers in either team being loaded with all the additional work (Meyer and Land 2003). Furthermore, this approach allows for the relevant expert to give the information. Team teaching also allays core course lecturer concerns about being uncomfortable with the subject and not delivering the correct information. Teamwork further means that core course lecturers (in this case PCS lecturers) are linked to the subject (HIV and AIDS) even though they may be not experts in it. However, they are the ones with the direct link to the student and are more likely to have the students' trust.

\section{'GRADUATENESS'}

Recent policy strategy at UCT has emphasised 'graduateness' as encapsulating attributes and skills that students require in preparation for the challenges of professional life (Conradie, Paxton and Skelly 2010). There are significant areas of overlap between UCT's conception of 'graduateness' and the requirements of the professional in engineering and built environment industries. With this analysis comes an increasing focus on ethics including social justice as a key area of 'graduateness'.

The particular strengths of PCS in presenting classes in a relaxed environment, in a workshop which encourages engagement (Stuart 2007), have meant that PCS is recognised as 
being well positioned to teach and facilitate the development of these professional skills (Gwynne-Evans and English 2014). In this regard, UCT adopted the term 'graduateness' to address and respond to these challenges. Out of this came six international graduate attributes:

- $\quad$ providing inclusive curricula and engagement with African voices;

- $\quad$ bringing research into teaching;

- $\quad$ preparing graduates for a global workplace;

- $\quad$ providing opportunities for more breadth within our undergraduate curriculum;

- $\quad$ ensuring graduates are critical thinkers and interested in post-graduate research;

- embracing the concept of graduateness which is seen to incorporate the 'skills, demeanour and values UCT hopes students will ... acquire by the time they leave UCT' (CHED 2010, 4).

\section{AIMS OF THE CURRICULUM INTEGRATION}

The aim of the intervention and research study in the University of Cape Town's (UCT) Engineering and the Built Environment (EBE) faculty by the HIV/AIDS Inclusivity and Change Unit (HAICU), a support division for students at UCT, was to provide knowledge and information; to engage staff and students at a personal and professional level; and to change staff and student attitudes and behaviours. The study was aligned with the aims of the National Department of Health (2012-2016 National Strategic Plan for HIV, STIs and TB), which addresses the structural, social, economic and behavioural factors driving the HIV and TB epidemics. The study aimed to answer questions raised by the HEAIDS (2010b) report as to the steps professional bodies in engineering could take to contribute to curriculum development concerning HIV and AIDS in South Africa (HEAIDS 2010b). The mode of delivery also aimed to respond to UCT's drive for cross-discipline research as it involved integration between the two departments, HAICU and PCS, and it was presented through workshops.

Finally, the intervention was also to meet UCT's drive to ensure all students have the qualities of 'graduateness' to take into their working lives.

\section{METHOD}

A mixed method research method was used to gather data during the course of the pilot programme. The research design was compromised of the following components. Firstly, a lecture on the applicability of the subject matter to industry was presented to the PCS staff. 
This lecture was followed by a discussion which resulted in the unanimous consensus that the PCS staff would support the pilot of this programme. Commitment to a topic is required for teachers to respond positively to teaching it. While the members of staff were not required to teach this topic, they did comment on the presentation's content and delivery during the practice-runs prior to the exam. PCS staff formed part of the assessment team and so it was important for them to be able to connect with the topic and the students, and so create an atmosphere of trust to enable the students to speak freely. To do this, HAICU supported PCS staff by educating the staff members about current developments in HIV education and treatment.

Secondly, a pre-assessment questionnaire, that is currently used by HAICU, was slightly adapted to include more industry specific questions, such as including workplace law. The HAICU questionnaire is based loosely on a Knowledge, Attitudes and Perceived Behaviour survey. However, the HAICU questionnaire differs in that there are many more open ended questions that require students to self-reflect. The pre-assessment also included some quantitative questions what asked students to consider what contextual issues may exacerbate new incidences of HIV. The pre-assessment was posted online to the course-specific student portal hosted at UCT. The students then had to anonymously complete the online questionnaire. The challenge in effective administration of questionnaires was to ensure that they reach the appropriate person, anonymous or known, and that they are completed. Thus, of the full cohort of 502 students, 56 volunteered to select a topic relating to HIV and AIDS to enter the competition and be part of the programme. UCT's ethics' requirements were met in that these students signed permission forms granting the researchers the right to use the data in papers or presentations.

The qualitative results of the pre-assessment were coded and analysed to produce key themes. Quantitative responses were analysed by the built in software in the student portal (VULA), to generate the percentages for each question.

The findings were then used to shape the content of the workshop that the students attended during the weekend. Students who attended the workshop did so voluntarily, and thus convenience sampling was the most suitable method for both students and the HAICU and PCS staff involved; the latter being sensitive to 'forcing' students to participate. Of the 56 students who completed the questionnaire, 41 students attended the 4-hour workshop given by HAICU and therefore constituted the final cohort who took part in the final study.

The workshop included input on gender-based violence and its management in the workplace, as well as the management of HIV and AIDS in the workplace. Care Works and 
the Power Group, a large Civil Engineering company working throughout Africa, also gave presentations. Care Works is private company (social enterprise) operating nationally in SA focussing on HIV and AIDS; it provides the following to companies (for example, to the Power Group): awareness-to-action training, counselling and testing; peer education training; on-going counselling and support for those testing HIV positive, and on-going treatment for HIV positive employees.

The workshop, with the involvement of these guest speakers from industry, focused on the students' roles and responsibilities as future managers. Thus the emphasis on HIV AND AIDS was less on personal experience and more on how it might affect their peer-group and future employees. This objectivity took personal pressure away from the participants.

Thus, the workshop content provided an overview of current challenges affecting industry and included possible topic areas that were relevant to industry. After the workshop, and over the course of several weeks, the students worked individually, to develop the presentation. During this period, students emailed the curriculum integration project officer at HAICU for advice and/or research material.

The penultimate stage of the research design was the oral assignment which was examinable and competitive; the highest scoring presentation would receive a prize. In pairs, students presented an oral presentation in answer to this question: 'HIV and AIDS: How does this affect the Engineering and the Built Environment Industry?' The criteria included giving a 10-minute presentation that used PowerPoint and meeting both PCS requirements in terms of delivery and HAICU requirements in terms of content. The final part of the programme was for the students to attend a focus group for post-assessment.

The last stage of the research was the post-assessment which was comprised of a focusgroup discussion. This final stage was incentivised, as students were entering the examination phase. Once again, a convenience sample was used and any of the students who participated in the HIV/AIDS module could attend.

\section{PRESENTATION OF RESULTS}

\section{Staff involvement}

The first outcome was the increase in HIV knowledge of the PCS staff involved in the course. The staff profile is part-time teachers of communication; all are women. The involvement of PCS staff in HAICU's work reflected the changing role of teachers to include becoming caring about social issues affecting their students. During the lecture and discussion in the 
first stage of the research design, staff admitted that they had considered themselves well versed in the subject but found they had much to learn, particularly in current industry practices.

\section{Pre-assessment}

The responses to the questions indicated that students had an accurate understanding of infection, transmission and treatment of HIV. It was, however, also evident, from the preassessment, that there were misconceptions and indicators of discrimination and stigma. Examples of this were various views that being HIV positive would have a negative impact on their functioning as effective managers, that is, on their 'graduateness' as engineers. Comments from the survey illustrating this negativity are the following which show discriminatory attitudes:

People with HIV and their loved one's fight for their rights; they are an unnecessary burden on the country. Instead of fighting poverty, the government must waste time and money on promiscuous peoples' bad decisions and their consequences.

The survey also indicated a lack of knowledge about management and treatment of the condition: 'HIV can be treated by the segregation of the infected'.

The survey highlighted the importance of HAICU providing the appropriate information and conducting a workshop with the students to engage in issues such as cultural influences, treatment and identity.

\section{Presentations}

For the PCS component, the students were required to research and present a talk. The brief given to the students was to select a topic focused on the work environment with an HIV AND AIDS theme. It had to be aimed at a realistic, mixed work-place audience (i.e., including specialist and non-specialist members) with a specific need for this information. The talk was to persuade an audience to change its attitude or to act on the information given - that is, for it to be more than a merely informative talk. The final presentation was marked for professional presentation skills by the PCS lecturer and judged for HIV AND AIDS content by adjudicators working in the HIV AND AIDS field.

A sample of topics given by the students as follows:

- $\quad$ HIV AND AIDS and Transparency in the Engineering Workplace 
- $\quad$ A Brighter Future for those working with HIV and AIDS

- $\quad$ Sexual Violence and HIV

- The Importance of Awareness of HIV and AIDS in the Workplace: its Effect on the Labour Force

- $\quad$ CareWorks and HIV management

All the talks were graded by PCS and HAICU, with the winning pair achieving 80 per cent. The focus group that followed analysed the generative learning (research, reflection, presentation) which had taken place. It was found that the workshop connected with the students' discipline, career path and 'graduateness'.

\section{Focus groups}

The focus group, meeting a month after the presentations, was comprised of six students. The poor attendance was attributed to the session falling in the examination period. The students received informed consent forms and the process and purpose of the focus group was explained. A voice recorder was used to record the focus group discussion, to assist in capturing the data for transcription and analysis. The focus group questions were developed from the data that emerged from the pre-assessment tool. Because the pre-assessment data was anonymous, it was not possible at this stage to triangulate the findings. However, the focus group provided an opportunity to discuss some of the pre-assessment findings and gain further insight.

The focus group questions were separated into three main areas of inquiry. The first few questions focused on the students' perceptions about the assimilation of HIV and AIDS into the PCS core course. The following conversation is evidence of the generative learning that had taken place and the role of the presentation exercise:

Student 5: It was a very good experiment to put it into professional communication because you (HAICU and PCS) were making us research on it and present back to you, so that was a very good setting.

Facilitator: Integrating it, and not just being talked at.

Student 5: Yes, having conversations about it.

Student 6: Yes, and it was persuasive, so you had to believe what you were saying and really get into it and convince everybody you were talking to. So, it was really good.

A wider assessment of the integration followed. One student observed: '... especially about the stigma, a lot of people actually used that in their presentation, which was quite good'. The 
students found the presentations by the independent companies enlightening, with an example comment being, 'I honestly did not know much about like you know [sic] how maybe industry is dealing with, companies are dealing with, HIV and all that, but these guys gave you a starting point'.

By focusing on making HIV education relevant to the discipline, students felt reassured about their purpose in being involved in the HIV workshop and were more aware about the challenges facing industry. The approach used by HAICU and PCS, therefore legitimized HIV education for the students, within the PCS engineering course.

The second set of questions focused on how the students thought they could practically apply the knowledge within industry. Comments were that this was the first time the students had seen a work place study around HIV and AIDS programmes. Most students felt that they themselves could apply the knowledge with practical outcomes in industry. An example of this was one student who considered changing company policies to allow for family to travel with migrant labour workers - to prevent sexual concurrency. However, one student felt cautious about being associated with anything HIV related, because he felt there was too much HIV stigma. He did however acknowledge that not being responsive to HIV prevention within industry would be problematic.

Although the HIV content was deemed relevant for students and most students in the focus group (five out of six students) felt that they could practically apply the knowledge to produce effective changes in industry - it was important for HAICU and PCS to consider how to educate students about interventions that could reduce HIV stigma, specifically, associated stigma.

Similarly, it was interesting to note why the students felt that the HIV education was of importance to them as budding engineers. A student's comment encapsulated the general perception that there was value in the education because, '... when we become managers, we are in top positions in companies, then we won't be discriminating against those with HIV. It's kind of a progressive thing, so instead of going straight to industry, you need to teach the people who will be in industry, so that at some point it's, like, common knowledge.'

The third topic was whether they felt their HIV presentation had influenced their peers who had not volunteered to be part of the programme. Predictably, responses were given around their friends having held misconceptions, as indeed they themselves had held, and now having the knowledge to change them. One student had the following to say:

Well, I must say, for me, like half my class was like why would you do that when you can present about cool engineering stuff? Like: that's what everyone was saying: 'You chose to do an HIV thing, really?' It was like guys were not keen about doing it, because they were like no, 
I'd rather do it about some cool gadget or whatever .... I spoke to one of my friends who was really interested in what we did, and she was like you know, I had no idea this is what they meant when they were saying doing the HIV thing. I think she had a misconception about it, because she really enjoyed my presentation. She was asking, she was like 'this is really cool and it’s really informative'. But initially they weren't keen, so I don't know what you have to do.

Similarly, another student made this comment on the learning experience:

I think the thing with most people is because they get a bit of information about HIV and AIDS, especially in first year, they think they know all there is to know about HIV and AIDS, so later on they are not so keen on progressing and learning more about it. Even me, I thought okay, there's no harm in knowing more, then I realised that actually, there isn't much that I knew before. So most people tend to think that they already know all there is to know about HIV and AIDS, but they are unaware that they still have got lots to learn about the topic.

This comment was particularly useful for HAICU and PCS for two reasons. Firstly, the statement confirmed that there is general apathy towards HIV education and that the most students feel they know a lot about HIV. Because of this, our second consideration was how we as educators introduce HIV as a potential topic within the PCS course, in order to not alienate students before they consider the topic as irrelevant.

\section{LIMITATIONS}

Both HAICU and PCS felt that there had been some successes experienced both in the pedagogy used and the students' engagement within the HIV-focused section of the PCS course. The students' feedback confirmed that focusing on the relevance of the HIV topic in a discipline specific way legitimized the HIV education within the course and exposed the broader challenges affecting industry. For example, one student indicated that, "The workplace focus stood out for me specifically, you couldn’t force people to get tested and yet some were victimised because of their status. These guys probably want to get tested but didn't want to share that information with the company.' Similarly, another student expressed that the legitimization of HIV education through core curricula is necessary, in order for graduates to remain cognizant of their role, once they graduate. The student claimed, 'When you get to industry you become oblivious to it [HIV and AIDS] and so it needs to be implemented into curriculum and related it to the discipline'.

Here we have shown that those that had voluntarily participated in the programme, initially had reservations about selecting the topic of HIV. These reservations were related to resistance towards the topic of HIV and not understanding how the knowledge would be any different to what they had learnt in their primary and secondary schooling. A secondary 
concern was related to the relevance of the topic to their discipline. These concerns were allayed once the students found that the HIV knowledge was vastly different to their existing knowledge. Students regarded the content as relevant to industry, upon realising their role (as dictated by South African legislation) as future managers and colleagues to people living with HIV. Once the students located the HIV education within industry, they understood how the education would enhance their own competency and professional skills, when working with or managing people living with HIV.

\section{CONNECTING THE PROFESSIONAL STANDARDS BODY TO HIV EDUCATION}

The Engineering Council of South Africa (ECSA) professional standards have broadly articulated what graduate attributes they would expect within industry. Students are expected to develop capabilities that not only prepare them to perform well as engineers but as professionals. Using HIV education to debate the intersectional challenges that affect professionals and influence workplace practices requires students to develop capabilities that move them beyond their subjective views. However, the opportunity to teach HIV within core curricula engineering subjects was largely based on the cooperation of the PCS staff members and the willingness of the students to voluntarily participate. The value of teaching about HIV education in an intersectional manner does lend itself to enriching students' graduate attributes as required by ECSA.

\section{CONCLUSIONS}

The conclusions were that overall collaboration between HAICU and PCS over including HIV input into the core curricula of the professional communication courses was effective and contributed to 'graduateness'. The exercise met the aspirations of the HEADS (2010a) and HEADS (2010b) reports needing HIV and AIDS awareness training integrated into core curricula. Through this successful response it also responded to the National Department of Health's strategic aims for management of HIV/AIDS. The decision to locate this intervention in the PCS course meant that the full spectrum of Faculty of EBE students were reached, albeit on a voluntary basis.

At no stage did the inclusion of the topic have a negative effect on the PCS course, and its course objectives were achieved. The HAICU objectives on developing workplace skills and competency in social and public health discourse were also achieved. And finally, perhaps most importantly, the students valued the integration of social and public health discourse. As it had been a first attempt, the course was voluntary. However, given its success 
for all role players, the final assessment of the study was to make the topic mandatory within a PCS course. This will mean every student, and not only volunteers, would be exposed to input on the topic and would participate in its assimilation. Thus the aims of the research study to set up a pilot study for mandatory inclusion were met. This was pursued in 2014.

\section{NOTES}

1 Note that in 2005, SAUVCA was incorporated into Higher Education of South Africa (HESA).

\section{REFERENCES}

Campbell, C. and F. Cornish. 2010. Towards a 'fourth generation' of approaches to HIV/AIDS management: creating contexts for effective community mobilisation. http://www.tandfonline. com/doi/abs/10.1080/09540121.2010.525812 (accessed 10.05.2015).

CHED see Council on Higher Education.

Conradie, B., M. Paxton and L. Skelly. 2010. What do graduate attributes mean for the classroom? The case of academic literacy in 3rd year economics. Presentation by Commerce Education Group, University of Cape Town, 11 May. http://www.commerce.uct.ac.za/Organisations/ CEG/Documents/2010/Academic literacy \& graduateness II - CEG 11 May 2010.pptx (accessed 27 July 2013).

Council on Higher Education. 2010. Teaching and learning at UCT: A report on the 2009 academic year. Council on Higher Education and Institutional Planning Department.

Dannels, D. 2002. Communication across the curriculum and in the disciplines: Speaking in Engineering. Communication Education 51(3): 254-268.

Gwynne-Evans, A. and J. English. 2014. Changes in teaching Graduate Skills, including ethics, since 2010. South African Journal of Higher Education 28(1): 110-127.

HEAIDS see Higher Education HIV/AIDS Programme.

HEAIDS see Higher Education HIV/AIDS Programme. 2006. HEAIDS strategic framework 20062009 and beyond. HESA: Pretoria. www.thutong.doe.gov.za/resourcedownload.aspx?id=27995 (accessed 5 April 2015).

Higher Education HIV/AIDS Programme. 2010a. HIV prevalence and related factors - Higher Education sector study, South Africa, 2008-2009. Pretoria: HESA.

Higher Education HIV/AIDS Programme. 2010b. Creating space for HIV and AIDS in the curriculum - A rapid assessment of curricular responses in South African Higher Education Institutions. Pretoria: HEAIDS Programme Report, 2002-2004.

Higher Education HIV/AIDS Programme. 2014. A desktop review of HIV and AIDS curricular responses in the higher education sector - with a particular focus on the local, African and internationally published literature. HESA: Pretoria. http://heaids.org.za/site/assets/files/1219/ desktop_research_paper_2104.pdf (accessed 5 April 2015).

Jennings, A. and J. D. Ferguson. 1995. Focusing on communication skills in Engineering education. Studies in Higher Education 20(3): 305-331.

Meyer, J. H. F. and R. Land. 2003. Threshold concepts and troublesome knowledge: Linkages to ways of thinking and practising within the disciplines. In Improving student learning: Improving student learning theory and practice - Ten years on, ed. C. Rust. Oxford: Oxford Centre for Staff and Learning Development.

Mkhize, N., J. Bennett, V. Reddy and R. Moletsane. 2010. The country we want to live in: hate crimes and homophobia in the lives of black lesbian South Africans. http://www.hsrcpress.ac.za/ 
product.php?productid=2282\&cat=1\&page=2\&freedownload=1 (accessed 15 March 2015).

Reave, L. 2004. Communication instruction in Engineering schools: A survey of top-ranked U.S. and Canadian programs. Journal of Business and Technical Communication 18: 452-490.

Simbayi, L. C., O. Shisana, T. Rehle, D. Onoya, S. Jooste, N. Zungu, D. Labadarios and K. Zuma. 2014. South African national HIV prevalence, incidence and behaviour survey, 2012. Pretoria: Human Sciences Research Council.

Stuart, J. D. 2007. From our frames: Exploring visual arts-based approaches for addressing HIV and AIDS with pre-service teachers (unpublished doctoral thesis). University of KwaZulu-Natal, Durban.

Sulcas, G. and J. English. 2010. A case for focus on professional communication skills at senior undergraduate level in Engineering and the Built Environment. Southern African Linguistics and Applied Language Studies on Language and Communication in Technical fields 28(3): 219-227.

Volks, C. 2012. Third degree: AIDS review. Pretoria: Centre for the Study of AIDS. 